\title{
Are all motivation tests the same? The effect of two adaptations to a three-chamber consumer demand study in ferrets
}

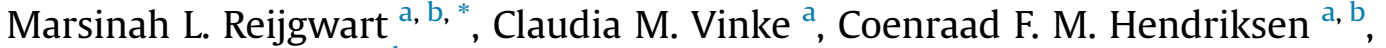 \\ Miriam van der Meer $^{\mathrm{b}}$, Nico J. Schoemaker ${ }^{\mathrm{c}}$, Yvonne R. A. van Zeeland ${ }^{\mathrm{c}}$ \\ a Department of Animals in Science \& Society, Faculty of Veterinary Medicine, Utrecht University, Utrecht, The Netherlands \\ ${ }^{\mathrm{b}}$ Institute for Translational Vaccinology (Intravacc), Bilthoven, The Netherlands \\ ${ }^{\mathrm{c}}$ Division of Zoological Medicine, Department of Clinical Sciences of Companion Animals, Faculty of Veterinary Medicine, Utrecht University, Utrecht, The \\ Netherlands
}

\section{A R T I C L E I N F O}

\section{Article history:}

Received 27 March 2017

Initial acceptance 10 May 2017

Final acceptance 26 September 2017

Available online 1 December 2017

MS number 17-00277R

\section{Keywords:}

consumer demand study

enrichment

ferret

maximum price paid

motivation
Ferrets, Mustela putorius furo, are increasingly used in infectious disease studies, particularly in influenza research. Which specific housing conditions and environmental enrichments are of particular importance for ferrets have not been part of a systematic evaluation. The motivation ferrets showed to reach different enrichments was assessed in multiple consumer demand study set-ups. To address the question whether these consumer demand set-ups give similar results, we assessed the effects of two ways of offering enrichments concurrently instead of consecutively. Six ovariectomized female ferrets were successively tested in a seven-chamber $(7 \mathrm{Ch})$, three-chamber $(3 \mathrm{Ch})$ and three-chamber 'all-butone' $(\mathrm{ABO})$ set-up. We compared the maximum price paid, visit number, visit duration and interaction time with the enrichments in the $3 \mathrm{Ch}$ versus the $7 \mathrm{Ch}$ and $\mathrm{ABO}$ set-ups, respectively. Compared to the $3 \mathrm{Ch}$ set-up, the ferrets in the $\mathrm{ABO}$ and $7 \mathrm{Ch}$ set-up showed a lower motivation to access, paid fewer and shorter visits to and interacted less with the enrichments. In the $7 \mathrm{Ch}$, the ferrets especially showed a lower motivation for the less preferred enrichments and the empty chamber. These findings indicate that testing all the enrichments concurrently in the 7Ch set-up forced the ferrets to make more economic decisions, thereby providing more valuable information on how different enrichments are valued relative to one other. Adding preferred enrichment items to the home chamber, as was done in the $A B O$ set-up, might have reduced the motivation to access or look for additional enrichment items. However, this set-up might not have a closed economy, making the ABO set-up unsuitable. Based on these findings, we advise testing all the enrichment categories concurrently instead of consecutively and keeping the number of items in the home cage to a minimum when performing a consumer demand study, as this appears the most optimal set-up to determine motivational priorities for resources in ferrets.

() 2017 The Association for the Study of Animal Behaviour. Published by Elsevier Ltd. All rights reserved.
Consumer demand studies are commonly used and regarded as a valid method to assess an animal's motivation for different types of environmental enrichment. This technique has been derived from human micro-economics and has been proposed as a tool to identify behavioural needs (Dawkins, 1983) as it can aid in understanding what animals 'want' (i.e. are motivated to access, Berridge \& Robinson, 2003). A consumer demand study uses an operant conditioning task in which the 'price' (e.g. number of responses) to

\footnotetext{
* Correspondence: M.L. Reijgwart, Department of Animals in Science \& Society, Faculty of Veterinary Medicine, Utrecht University, P.O. Box 80166, 3508 TD Utrecht, The Netherlands.

E-mail address: M.L.Reijgwart1@uu.nl (M. L. Reijgwart).
}

gain access to a resource is increased or the available 'income' (e.g. available time to respond) is decreased (Cooper \& Mason, 2001; Dawkins, 1990). Ultimately, the 'price' an animal is willing to pay for access to an enrichment indicates the motivation an animal has to reach it, and how important it is for that animal to have access to that specific enrichment (Kirkden \& Pajor, 2006). Consumer demand studies are therefore often used to substantiate which changes to an animal's housing should be made to improve their welfare (e.g. Mason, Cooper, \& Clarebrough, 2001; Seaman, Waran, Mason, \& D'Eath, 2008).

Reijgwart et al. (2015) designed a two-chamber consumer demand study to identify enrichments that could be provided to ferrets, Mustela putorius furo, to refine studies using these animals. 
This set-up proved to be unsuitable to test ferrets, however, as they would push to their maximum ability to reach an empty chamber. This study further indicated that the items in the home chamber influenced the ferrets' motivation to enter an empty chamber. The subsequent search for a suitable consumer demand set-up for ferrets resulted in two possible alternative set-ups: a three-chamber and a multichamber set-up (e.g. Hovland, Mason, Bøe, Steinheim, \& Bakken, 2006; Mason et al., 2001; Seaman et al., 2008). It was not clear, however, whether these set-ups would give similar results when applied to ferrets.

In the literature, there are many issues regarding how a consumer demand study can optimally be designed and interpreted. First, an animal should be tested in a closed economy (i.e. only providing access to the enrichment during the experiment), as testing in an open economy (i.e. giving the animals access to the enrichments outside the test environment) might lower the motivation for enrichments in the study (Ladewig, Sørensen, Nielsen, \& Matthews, 2002; Mason, McFarland, \& Garner, 1998). Second, a naturalistic operant task (such as a push door or a narrow gap) should be used, as it requires little training and is least prone to operant-reinforcer bias (Cooper, 2004; Kirkden, Edwards, \& Broom, 2003; Mason et al., 1998). Third, the maximum price paid (MPP) or reservation price index, the price at which the animal is no longer willing to perform the task, should be used to calculate the animal's motivation as it is considered the most appropriate for the assessment of unsubstitutable, discrete and indivisible resources such as enrichments (Cooper, 2004; Cooper \& Mason, 2001; Jensen \& Pedersen, 2008; Mason et al., 1998). Fourth, to be able to interpret the price the animals pay for resources correctly, it is vital to determine the negative control (i.e. the minimum price the animal will pay) and positive control (i.e. the maximum price the animal is able to pay; Dawkins, 1983). As a negative control, the animal's motivation for an empty chamber is often measured in order to quantify how motivated the animal is to reach additional space and/or to perform the task itself. As a positive control, the animal's maximum push capacity (MPC), that is, the maximum effort that the animal is able to exert to accomplish the task, is established. This parameter can be used as a yardstick to relate the findings to. The animal's motivation for food or water is often used as the MPC as these are essential needs, for which the animal will presumably perform to its maximum ability (Dawkins, 1983; Matthews \& Ladewig, 1994). These minimum and maximum motivation levels can subsequently be used to determine where on the motivational scale the values of different enrichments lie.

To our knowledge, whether offering enrichments concurrently or consecutively affects the results obtained in consumer demand studies has not been studied. Therefore, we compared the results of a three-chamber ( $3 \mathrm{Ch})$ consumer demand set-up with a sevenchamber (7Ch) set-up (comparison 1 ). Additionally, we compared the results of the $3 \mathrm{Ch}$ set-up with the results of a three-chamber 'all-but-one' (ABO) set-up (comparison 2) to assess the effect of adding freely available enrichment items to the home chamber. In the 7Ch set-up, the ferrets are expected to make more economic choices than in the 3Ch set-up, in view of the limited time (and energy) available to work for and visit the concurrently provided enrichment items. In the ABO set-up, the ferrets are expected to be less motivated to access additional enrichment items than in the $3 \mathrm{Ch}$ set-up, as there are highly valued items freely available in the home chamber already fulfilling some motivations. We therefore predicted that offering the enrichments concurrently in the 7Ch set-up and adding enrichment items to the home chamber in the ABO set-up would result in a lower MPP, visit number, visit duration and interaction time with the enrichments than in the 3Ch set-up.

\section{METHODS}

\section{Ethical Note}

This study was ethically approved by the Animal Care and Use Committee of the Institute for Translational Vaccinology (Intravacc, DEC 201400137). As this was a study into the enrichment priorities of ferrets, there were few welfare implications. The ferrets were housed alone when they were being tested, which might have caused some distress. However, it is not yet determined whether ferrets are a truly social species (i.e. whether they suffer when housed alone). In the 7Ch set-up, the ferrets could always push a door to gain access to conspecifics.

\section{Animals, Housing and Husbandry}

For the study, six female surgically neutered (ovariectomized) ferrets were used that were obtained from Schimmel B.V. (Scherpenzeel, Netherlands), weighed $1035 \pm 131 \mathrm{~g}$ and were approximately 1 year old at the start of the experiment. The ferrets were ovariectomized to prevent the onset of oestrus, which could affect their behaviour and might lead to anaemia, weight loss, alopecia and even bone marrow depression if the animal is not bred (Fox, Bell, \& Broome, 2014). The ferrets were housed under the conditions described in Reijgwart et al. (2016), namely indoors, between $19{ }^{\circ} \mathrm{C}$ and $23^{\circ} \mathrm{C}$, on an 8:16 h light:dark schedule with auditory stimulation. They were group housed between experiments in floor pens $(163 \times 94 \mathrm{~cm})$ with sawdust, a flexible plastic bucket and ad libitum water (from a nipple) and food (ferret balance pellets in a stoneware bowl; Hope Farms, Woerden, Netherlands). The ferrets' health and overall condition were monitored prior to and throughout the study.

\section{Enrichments}

Enrichments from six different enrichment categories were tested: sleeping enrichment, water enrichment, foraging enrichment, social enrichment, tunnels and balls; Table 1).

These enrichment categories were chosen to accommodate behaviours seen in feral ferrets, where each category represents a different behavioural motivation (see Reijgwart et al., 2016). For each enrichment category two or three items with different characteristics were offered in one enrichment chamber to increase the chance of testing the motivation for the preferred item within the category. These items were chosen based on variability within a category and practicality in a laboratory setting. Additionally, an empty chamber was tested to control for the value of extra space, patrolling and the rewarding properties of the task itself (i.e. negative control). Food was used as a resource to serve as a positive control, that is, to determine the MPC of the ferrets (see Reijgwart et al., 2015).

\section{Experimental Housing}

During the experiment, the ferrets were subsequently individually housed in three types of closed-economy consumer demand set-ups, each consisting of one home chamber, an empty control chamber and either one or six enrichment chambers for the $3 \mathrm{Ch}$ or 7CH set-up, respectively.

\section{Apparatus}

Between the chambers there was a $70 \mathrm{~cm}$ high, $6 \mathrm{~mm}$ thick phenolic-faced plywood divider. The divider was equipped with a mesh window through which the ferrets could see whether and which items were present in the chamber. This was done to ensure that the ferrets were always aware of the items present in each 
Table 1

Overview of the enrichments in each enrichment category

\begin{tabular}{|c|c|c|}
\hline $\begin{array}{l}\text { Enrichment } \\
\text { category }\end{array}$ & Enrichments & Specifications \\
\hline \multirow[t]{3}{*}{ Sleeping } & Bucket & Flexible plastic bucket ${ }^{1}$ \\
\hline & Savic Cocoon & Savic Cocoon, $34.5 \times 26.5 \mathrm{~cm}$ and $16.0 \mathrm{~cm} \mathrm{high}^{1}$ \\
\hline & Hammock & Adori hammock, $50 \times 45 \mathrm{~cm}^{1}$ \\
\hline \multirow[t]{2}{*}{ Water } & Large bowl & $\begin{array}{l}\text { Marchioro kitten litterbox filled with water, } \\
26 \times 36 \mathrm{~cm} \text { and } 9 \mathrm{~cm} \text { high }^{1}\end{array}$ \\
\hline & Small bowl & $\begin{array}{l}\text { Adori stoneware food bowl filled with water, } \\
\text { diameter } 18 \mathrm{~cm}, 5 \mathrm{~cm} \text { high }^{1}\end{array}$ \\
\hline \multirow[t]{2}{*}{ Foraging } & Foraging ball & Happy Pet tumble 'n treat, diameter $6 \mathrm{~cm}^{1}$ \\
\hline & Tumbler & Nina Ottoson Cat pyramid, $9.5 \mathrm{~cm}$ high $^{2}$ \\
\hline Social & Conspecifics & Two familiar female ferrets ${ }^{3}$ \\
\hline \multirow[t]{2}{*}{ Tunnels } & Rigid tunnel & $\begin{array}{l}\text { Ferplast tunnel FPI } 4840 \text {, diameter } 10.5 \mathrm{~cm} \text {, } \\
\text { length } 29 \mathrm{~cm}^{1}\end{array}$ \\
\hline & Flexible tunnel & $\begin{array}{l}\text { Zooplus 260697.0, diameter } 10 \mathrm{~cm} \text {, length } 19 \\
-75 \mathrm{~cm}^{4}\end{array}$ \\
\hline \multirow[t]{3}{*}{ Balls } & Ball with bell & Cat play ball ${ }^{1}$ \\
\hline & Golf ball & Diameter $4 \mathrm{~cm}$ \\
\hline & Ferret ball & $\begin{array}{l}\text { Ferret ball, diameter } 25 \mathrm{~cm}, 4 \text { holes diameter } \\
10.2 \mathrm{~cm}^{5}\end{array}$ \\
\hline
\end{tabular}

Superscript numbers indicate the supplier of the enrichment. $1=$ van der Neut, Groenekan, The Netherlands, 2 = onlinedierenspeciaalzaak.com, 3 =Schimmel BV, The Netherlands, 4 = zooplus.nl, 5 = Tecnilab-BMI, Someren, The Netherlands.

enrichment chamber rather than having to learn and memorize the locations of each of these, which might have been more difficult in the 7Ch set-up than in the 3Ch set-up. In addition, a nontransparent one-way cat flap and a one-way horizontal swinging weighted door (Tecnilab-BMI, Someren, The Netherlands) were mounted in the divider. Under the doors, a wire mesh strip was mounted to provide a traction surface for the ferrets to facilitate the application of force to the doors. The doors allowed the ferrets to move from the home chamber/corridor to the empty control chamber and the enrichment chamber(s), whereas the one-way unweighted cat flap could be used by the ferrets to return to the home chamber/corridor.

\section{Operant Task}

The naturalistic operant task chosen for this study included pushing open a weighted door. Opening the unweighted door required the ferrets to exert a force of $200 \mathrm{~g}$. By adding weights to the door mechanisms, the effort needed to open the doors could be gradually increased. The mechanism was designed in such a way that $50 \%$ of the added weight was transferred to the actual force needed for the ferret to open the door. Thus, a weight of $500 \mathrm{~g}$ translated to a push force of $450 \mathrm{~g}(200+50 \%$ of $500 \mathrm{~g})$, a weight of $1000 \mathrm{~g}$ to a push force of $700 \mathrm{~g}(200+50 \%$ of $1000 \mathrm{~g})$, etc. For all setups, the weight added to the mechanism was increased daily by $500 \mathrm{~g} /$ day up to $3000 \mathrm{~g}$ (i.e. a push force of $1700 \mathrm{~g}$ ), which was established to be just above the maximum push capacity of the ferrets $(1450 \pm 144 \mathrm{~g}$, Reijgwart et al., 2015). Ferrets were considered to have reached their MPP (i.e. the maximum weight the animal was prepared to push) for a particular enrichment category or the empty chamber when they did not visit the chamber of that category for $24 \mathrm{~h}$. MPP was recorded as the last weight successfully pushed to gain access to the chamber.

\section{Acclimatization and Training}

The ferrets were allowed to acclimatize to the experimental housing for 7 days prior to commencing each experiment. During this period, all doors were closed but unweighted. The ferrets had been trained to use the weighted door with food as a reinforcer in a previous experiment (Reijgwart et al., 2015) and no additional training was required.

\section{Study Design}

Ferrets were tested in three different set-ups: 7Ch (seven chambers), 3Ch (three chambers) and ABO (three chambers with freely available enrichment items in the home chamber). The setups were kept as similar as possible (except for the simultaneous provision of enrichment). For logistical reasons, the order in which the set-ups were tested was the same for each ferret.

\section{Experimental set-up 1: 7Ch (comparison 1)}

The 7Ch set-up was used to determine the motivation of ferrets for enrichments that were concurrently presented in adjacent chambers. This set-up consisted of one home corridor $(692 \mathrm{~cm}$ long, $54 \mathrm{~cm}$ wide) connected to seven phenolic-faced plywood floor pens (ground surface $107 \times 94 \mathrm{~cm}$ ): one empty control chamber and six enrichment chambers. The home corridor contained ad libitum food (Hope Farms ferret balance pellets) in a bowl and water from a nipple. In each of the six enrichment chambers, there were items from one of the enrichment categories (i.e. sleeping, water, foraging, social contact, tunnels and balls). The locations of the control and enrichment chambers were randomized between ferrets (Fig. 1a; Reijgwart et al., 2016).
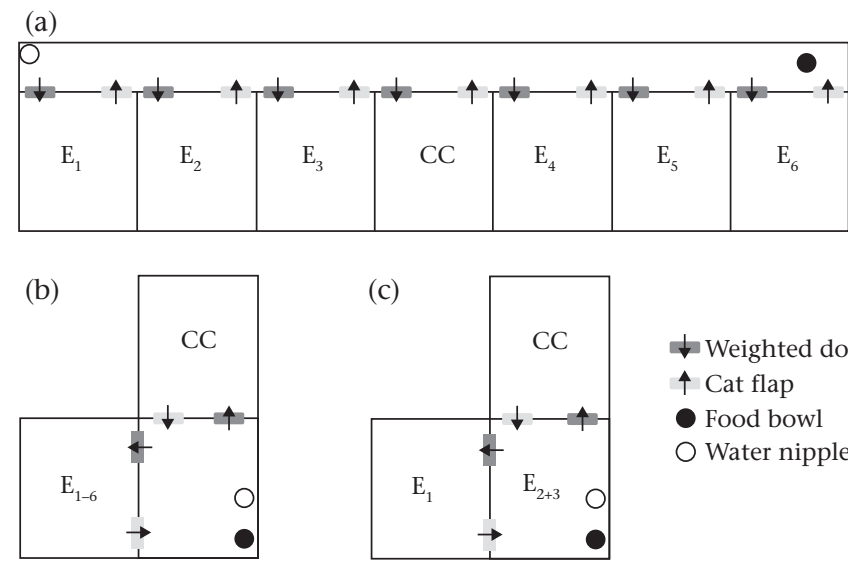

$$
\begin{aligned}
& \downarrow \text { Weighted door } \\
& \uparrow \text { Cat flap } \\
& \text { Food bowl } \\
& \text { Water nipple }
\end{aligned}
$$

Figure 1. Design of the (a) seven-chamber, (b) three-chamber and (c) all-but one consumer demand set-ups. $\mathrm{E}_{1-6}=$ enrichment chambers $1-6 ; \mathrm{CC}=$ empty control chamber.

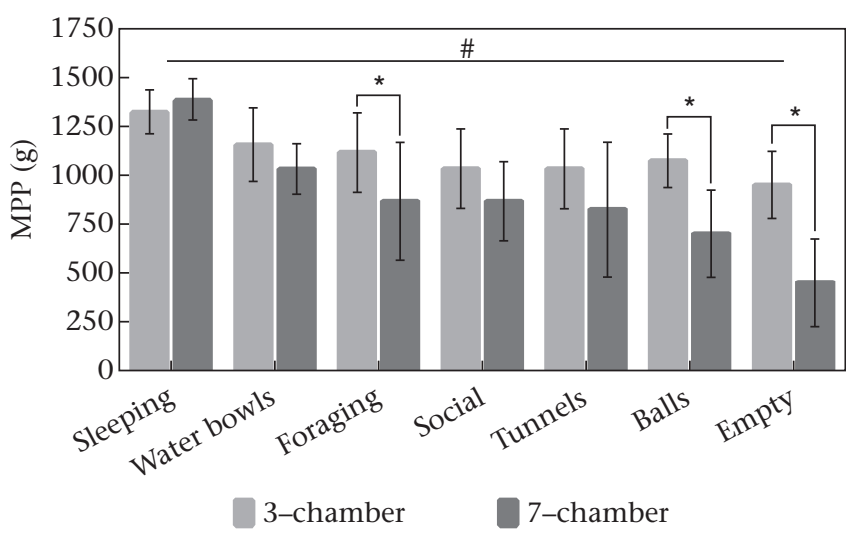

Figure 2. The maximum price paid (MPP) by ferrets for the different enrichment chambers (with sleeping enrichment, water enrichment, foraging enrichment, social enrichment, tunnels, balls and an empty chamber) in the three-chamber versus the seven-chamber set-up of the consumer demand study (mean $\pm \mathrm{SD} ; N=6$ ferrets per set-up; \#indicates an overall difference between the set-ups with $P<0.014$; *indicates a significant interaction effect between set-up and enrichment with $P<0.014$ ). 


\section{Experimental set-up 2: 3Ch (comparisons 1 and 2)}

The $3 \mathrm{Ch}$ set-up was used to determine the motivation of ferrets for enrichments that were consecutively presented. This set-up was used as a comparison for both the 7Ch and the $\mathrm{ABO}$ set-up and consisted of one home chamber, one empty control chamber and one enrichment chamber that each measured $95 \times 80 \mathrm{~cm}$. The home chamber had ad libitum food (Hope Farms ferret balance pellets) in a bowl, water from a nipple and a sleeping bucket (except when testing the sleeping enrichment). Items from one of the enrichment categories that were also tested in the 7Ch (i.e. foraging toys, social contact, sleeping, water, tunnels and balls) were placed in the enrichment chambers in random order. The locations of the control and enrichment chambers and the order in which the enrichment categories were tested were randomized between enrichment categories and between ferrets (Fig. 1b).
Experimental set-up 3: ABO set-up (comparison 2)

The ABO set-up was used to determine the motivation of ferrets for enrichments when there were also freely available enrichments in the home chamber. Based on the findings of the 7Ch set-up, the enrichments from three enrichment categories for which the ferrets were most motivated and with which they interacted most were selected to be tested in comparison 2 (sleeping, water and foraging). The $\mathrm{ABO}$ set-up was identical to the $3 \mathrm{Ch}$ set-up described above, except that the home chamber was equipped not only with food, water and a sleeping bucket (except when testing the sleeping enrichment), but also enrichments from two of three enrichment categories (sleeping, water bowls, foraging). Items from the third enrichment category (not present in the home chamber) were placed in the enrichment chamber. Similar to the 3Ch set-up, the locations of the enrichment and control chambers and the order in
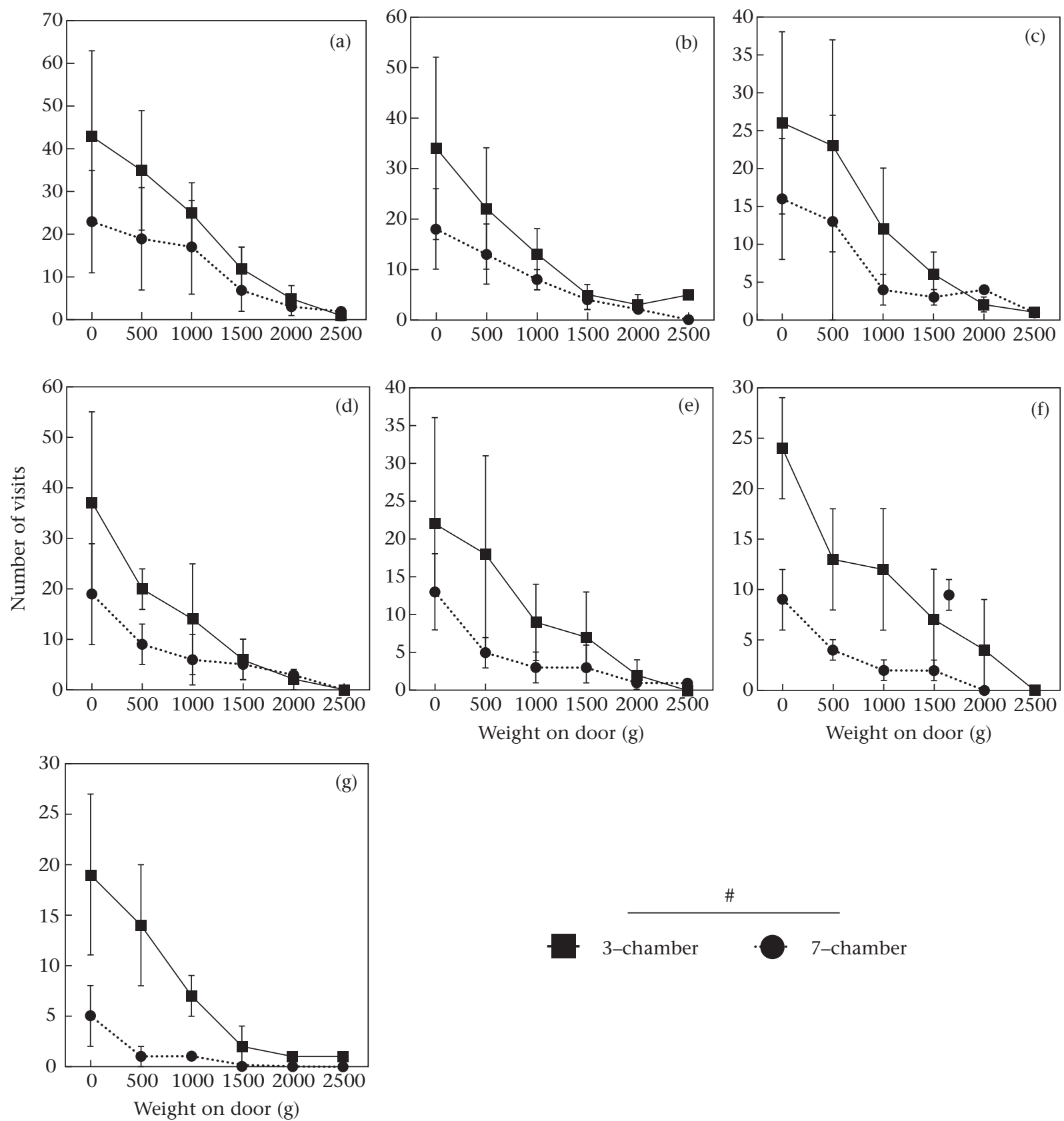

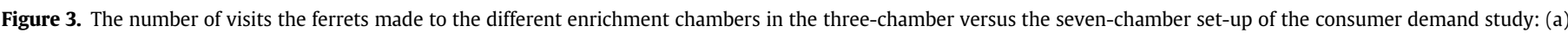

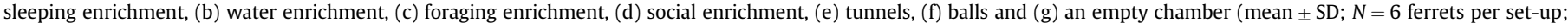
\#indicates an overall difference between the set-ups with $P<0.014$ ). 
which the enrichment categories were tested were randomized between enrichment categories and between ferrets (Fig. 1c).

\section{Measurements}

Four different parameters were recorded in the three consumer demand set-ups: MPP, number and duration of visits to the enrichment chamber(s) and interaction with enrichments. The MPP was defined as the maximum weight ( $\mathrm{g}$ ) the ferret pushed to gain access to a resource. The total visit number, visit duration and enrichment interaction time for each weight (i.e. per $24 \mathrm{~h}$ ) were calculated from the videotaped behaviour in the enriched chambers. For social contact and the empty control chamber, only MPP, visit number and duration were noted. When a ferret made no visits to a resource at a given weight, visit number, visit duration and enrichment interaction time were noted as missing values.

\section{Statistical Analysis}

Analyses were performed using SPSS software (version 24.0, IBM, Armonk, NY, U.S.A.). Data were expressed as mean \pm SD and
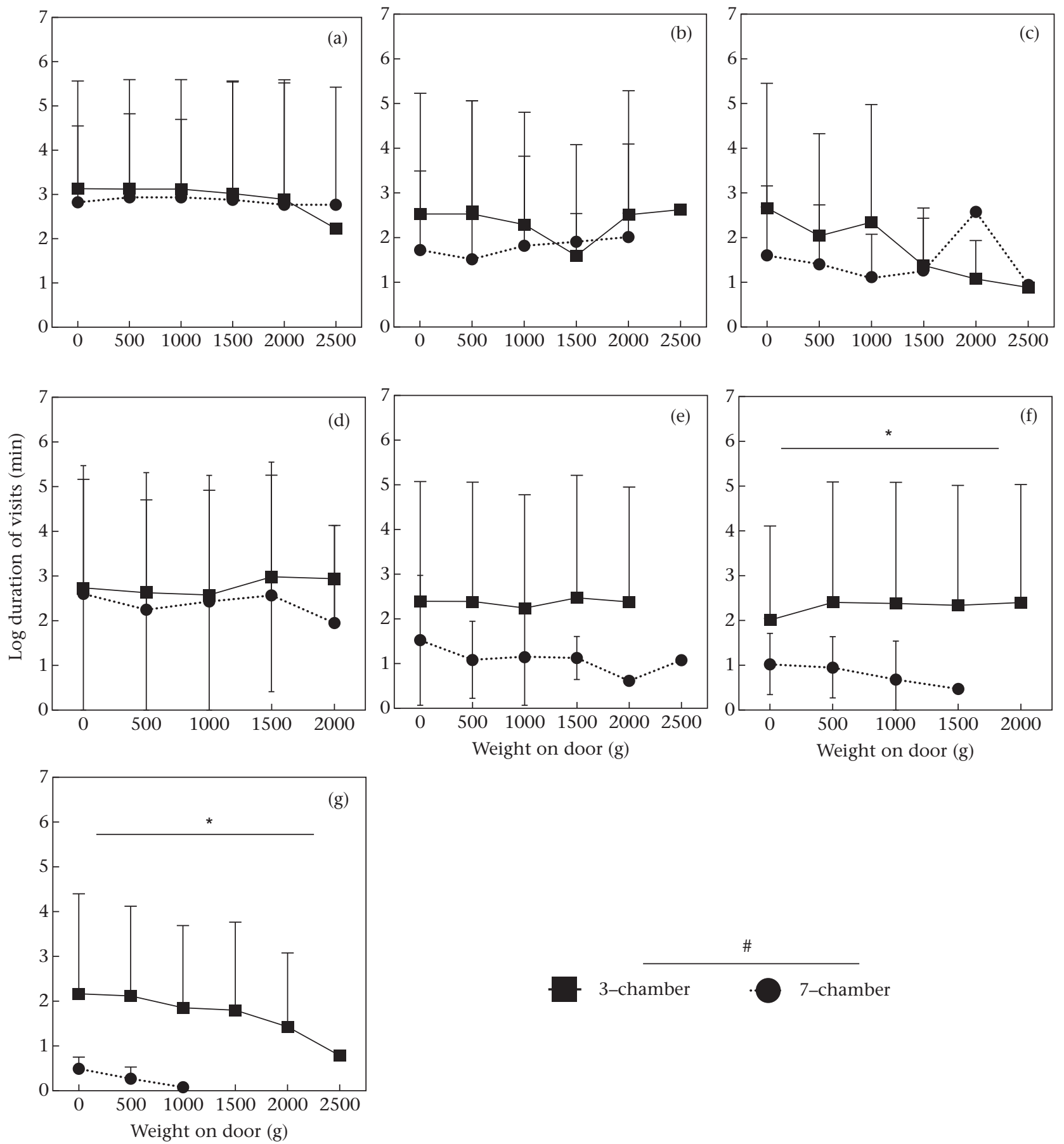

\#

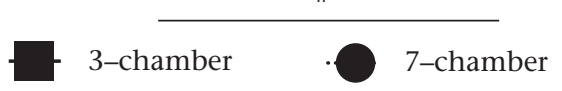

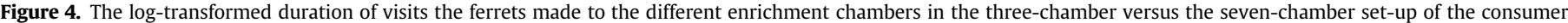

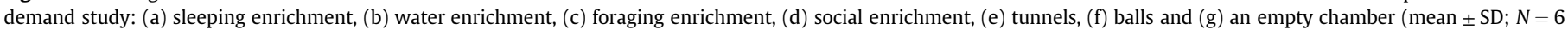

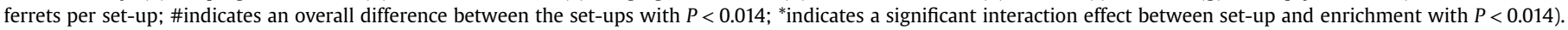


duration of visits was log transformed to ensure normality of data distribution. The probability level accepted for statistical significance $(P<0.05)$ was corrected with the false discovery rate (FDR; Benjamini, Drai, Elmer, Kafkafi, \& Golani, 2001) to guard against type I errors when performing multiple comparisons.

Differences in MPP, visit number, visit duration and enrichment interaction between the $3 \mathrm{Ch}$ and the 7Ch set-up and between the $3 \mathrm{Ch}$ and the $\mathrm{ABO}$ set-up were analysed with a linear mixed model (LMM) using a compound symmetry structure, with ferrets as subject and set-up, enrichment, order and weight (not for MPP) as repeated factors. In the model, MPP, visit number, visit duration and enrichment interaction were entered as dependent variables, set-up, enrichment, set-up*enrichment and weight (not for MPP) as fixed factors, and order of enrichments (nested within ferret) and ferret as random factors. Sum contrasts were used for the fixed factors. Post hoc comparisons were made for the set-up*enrichment effects when there was an overall interaction effect.

\section{RESULTS}

\section{Comparison 1: 3Ch Versus 7Ch Set-up}

The LMM analysis revealed that the 7Ch set-up yielded lower MPPs than the 3 Ch set-up $\left(F_{1}, 19.433=36.210, P<0.001\right)$. There was also an interaction effect between set-up and enrichment on MPP $\left(F_{6}, 98.375=4.705, P<0.001\right)$, indicating that the difference in MPP was most pronounced for foraging enrichment, balls and empty $(P=0.010, P<0.001$ and $P<0.001$, respectively; Fig. 2$)$.

The ferrets paid fewer visits to the enrichment chamber in the 7Ch than in the 3 Ch set-up (LMM: $F_{1,20.369}=128.633, P<0.001$ ). There were no interaction effects between set-up and enrichment on visit number (LMM: $F_{6}, 394,468=0.843, P=0.537$; Fig. 3 ).

The ferrets paid shorter visits to the enrichment chambers in the 7Ch than in the 3 Ch set-up (LMM: $F_{1,21.765}=30.670, P<0.001$ ). There was also an interaction effect between set-up and enrichment on visit duration (LMM: $F_{6,389.265}=6.782, P=0.005$ ), indicating
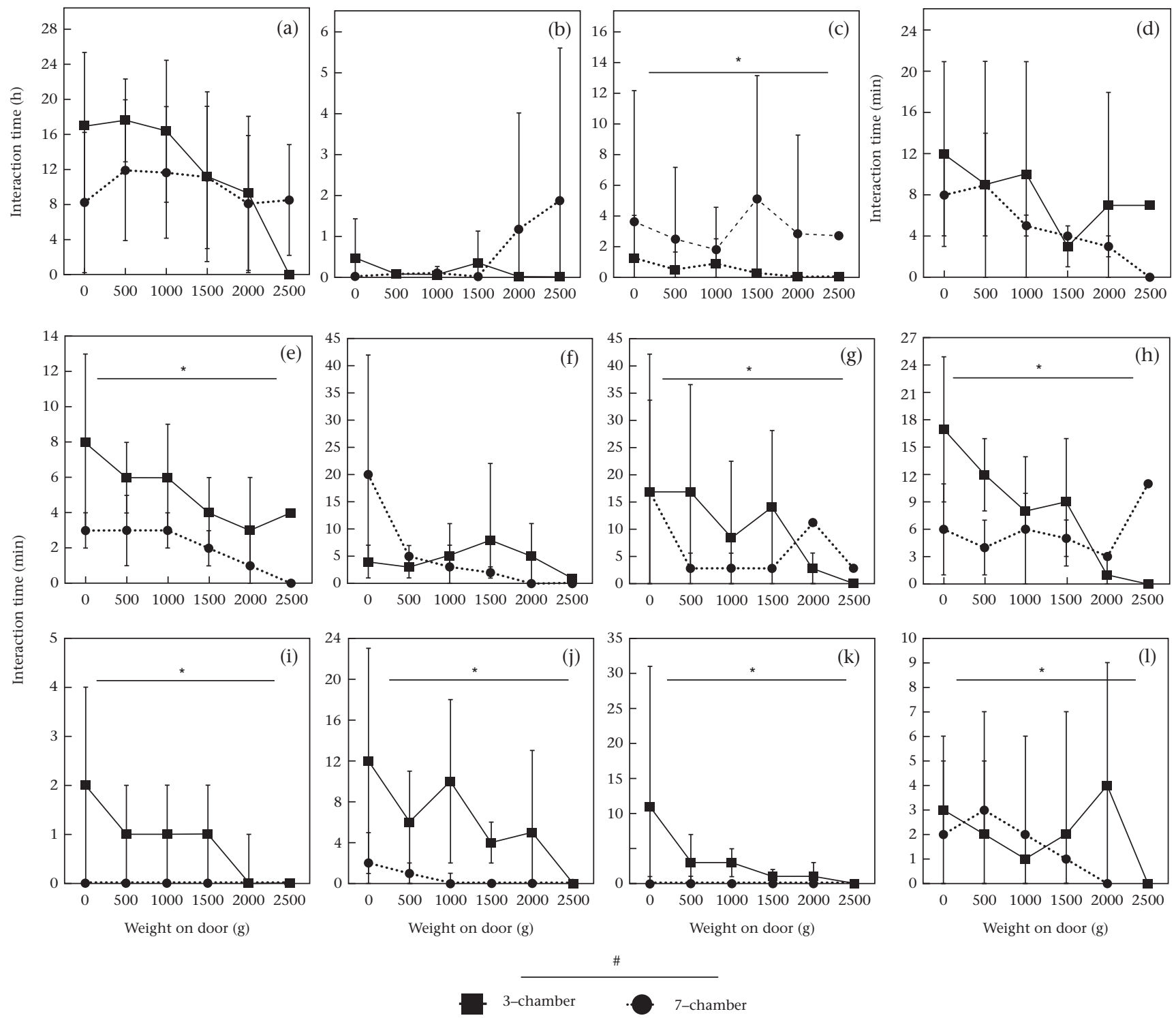

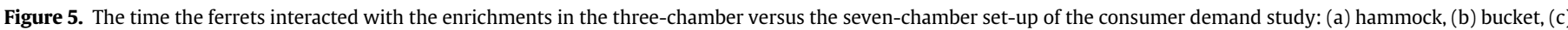

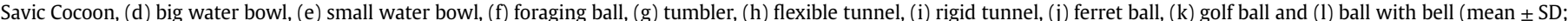

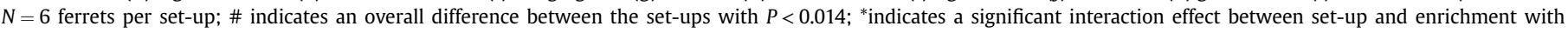


that the difference in visit duration was most pronounced for balls and empty $(P=0.001$ and $P<0.001$, respectively; Fig. 4$)$.

The ferrets interacted for less time with the enrichments in the 7Ch than in the 3 Ch set-up (LMM: $F_{1,1907.918}=128.566, P<0.001$ ). There was also an interaction effect between set-up and enrichment for interaction time (LMM: $F_{11,1809.668}=8.030, P<0.001$ ), indicating that the difference in interaction time was most pronounced for the Savic Cocoon, small water bowl, tumbler, flexible and rigid tunnels, ferret ball, golf ball and ball with bell $(P<0.001$ for all; Fig. 5).

\section{Comparison 2: 3Ch Versus ABO Set-up}

Based on the findings of the 7Ch, three enrichment items for which the ferrets were most motivated were selected to be tested in comparison 2. During the ABO set-up, one of the ferrets learned to circumvent pushing the door; therefore, her results were removed from the statistical analysis.

The LMM analysis revealed that, overall, the MPPs were lower in the $\mathrm{ABO}$ than in the $3 \mathrm{Ch}$ set-up (LMM: $\left.F_{1,78.592}=11.235, P=0.001\right)$. There were no interaction effects between set-up and enrichment on $\operatorname{MPP}\left(F_{3,54.291}=0.166, P=0.919\right.$; Fig. 6$)$.

The visit numbers were lower in the ABO set-up than in the $3 \mathrm{Ch}$ set-up (LMM: $F_{1,295.370}=9.867, P=0.002$ ). There were no interaction effects on visit number between the $3 \mathrm{Ch}$ and $\mathrm{ABO}$ set-up (LMM: $F_{3,290.371}=2.222, P=0.086$; Fig. 7 ).

Overall, the visit durations were lower in the $A B O$ than in the 3 Ch set-up (LMM: $F_{1,83.470}=10.593, P=0.002$ ). There were no interaction effects between set-up and enrichment on visit duration (LMM: $F_{3,112.805}=2.730, P=0.047$; Fig. 8 ).

Overall, the ferrets interacted less with the enrichments in the ABO than in the 3 Ch set-up (LMM: $F_{1,318.277}=10.549, P=0.001$ ). There were no interaction effects between set-up and enrichment on enrichment interaction (LMM: $F_{6,319.398}=0.397, P=0.881$; Fig. 9).

\section{DISCUSSION}

This study investigated whether testing enrichments concurrently instead of consecutively (comparison 1) and providing a

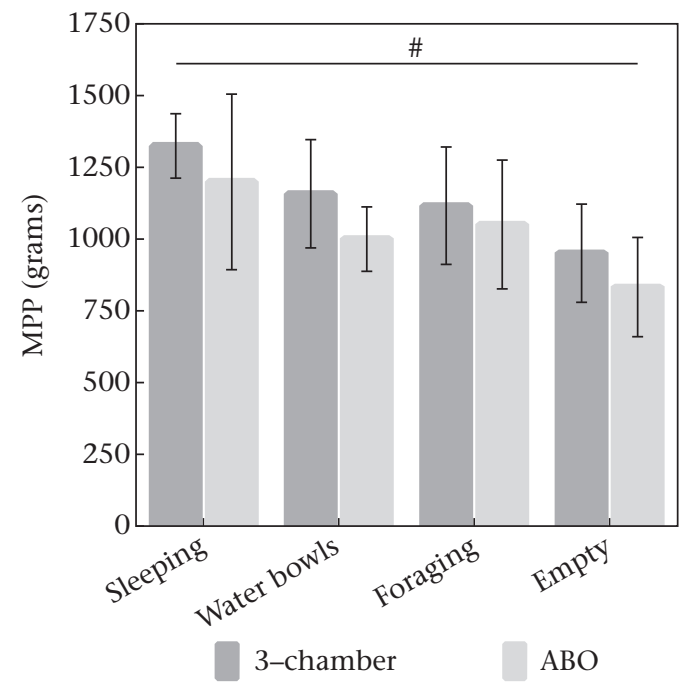

Figure 6. The maximum price paid (MPP) by the ferrets for the different enrichment chambers (with sleeping enrichment, water enrichment, foraging enrichment and an empty chamber) in the three-chamber versus the ABO set-up of the consumer demand study (mean $\pm \mathrm{SD} ; N=6$ ferrets in the three-chamber set-up and $N=5$ ferrets in the $\mathrm{ABO}$ set-up; \#indicates an overall difference between the set-ups with $P<0.014$ ). freely available enrichment item in the home chamber (comparison 2 ) influenced the results of a consumer demand study.

\section{Comparison 1: 3Ch Versus 7Ch Set-up}

As expected, the ferrets showed a lower motivation to enter the enrichment chambers, interacted less with the enrichments and paid fewer and shorter visits to them when they were tested concurrently compared to consecutively, especially for the less preferred enrichments (tunnels and balls) and the empty chamber.

There are three possible explanations for these findings. First, in the 7Ch set-up, the ferrets had more enrichment chambers to choose from than in the 3Ch set-up. In this way, the 7Ch set-up limited the available time for each chamber/enrichment category. These time constraints have been shown to differentially affect time spent on activities in dairy cows (Munksgaard, Jensen, Pedersen, Hansen, \& Matthews, 2005). Likewise, the time constraints in the 7Ch set-up might have forced the ferrets to make more economic choices. Essentially both the animals' income (i.e. time per enrichment) and the price of the enrichments (i.e. weight of the door) were manipulated in the 7Ch set-up, whereas only the latter was increased in the $3 \mathrm{Ch}$ set-up. This might have caused the ferrets to reduce 'luxury behaviour' such as interacting with a ball and exploring the empty chamber in the 7Ch set-up to defend the time and energy needed for essential behaviours (as suggested by Houston \& McFarland, 1980).

Alternatively, the provision of multiple choices might have had enriching capacities (as suggested by Hutchinson, 2005). For example, giant pandas, Ailuropoda melanoleuca, and polar bears, Ursus maritimus, that were given the choice to access an alternative (less enriched) space showed signs of improved welfare (Owen, Swaisgood, Czekala, \& Lindburg, 2005; Ross, 2006). The increased choices offered in the 7Ch might therefore have resulted in a loss of interest and lower motivation for less valued enrichments and the empty chamber. This might especially be true for enrichment options that are, in part, substitutes and allow for performance of similar behaviours (Kirkden \& Pajor, 2006). For example, the foraging ball provided the ferrets with similar opportunities as regular balls, next to the opportunity to forage. Alternatively, choice aversion, that is, a decline in choice behaviour due to too much choice, might explain the lower motivation in the 7Ch set-up (Hutchinson, 2005). However, this is not likely to have occurred, as in that case interest and motivation for all enrichment categories would have declined equally and to a greater extent.

Finally, it is possible that the ferrets experienced too little stimulation in the $3 \mathrm{Ch}$ set-up compared to the more complex $7 \mathrm{Ch}$ set-up. Similar to rats, Rattus norvegicus, that explored more when housed in unenriched cages (Abou-Ismail, Burman, Nicol, \& Mendl, 2010), the impoverished 3Ch set-up might have resulted in more novelty-seeking visits to the empty control chamber compared to the 7Ch set-up (Abou-Ismail et al., 2010).

These explanations all favour the 7Ch set-up as the most useful design to assess the value of enrichment items for ferrets, as, in a consumer demand study, we want the animals to make economic choices and show a low motivation for the least valued enrichments and we want to prevent novelty seeking.

However, it should be taken into account that in the 3Ch set-up, the location of the enrichment chamber and empty control chamber were randomized between enrichment categories, which was not possible in the 7Ch set-up as all the enrichment chambers and the empty control chamber remained at the same location throughout the test per ferret and could only be randomized between ferrets. In the 3 Ch set-up, this might have made the environment in both chambers unpredictable, which has been suggested to increase exploration (with the aim of learning about 

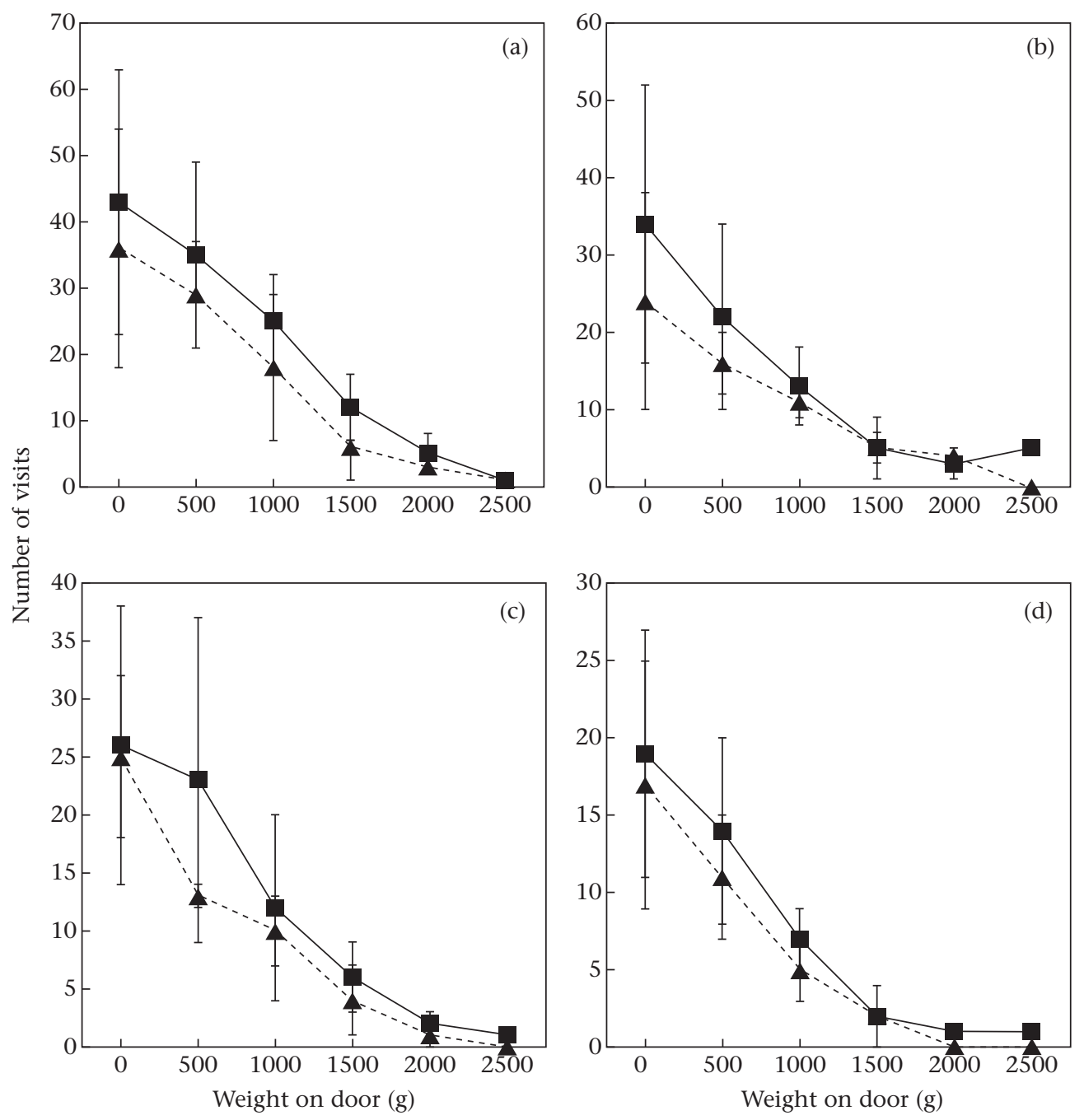

\#

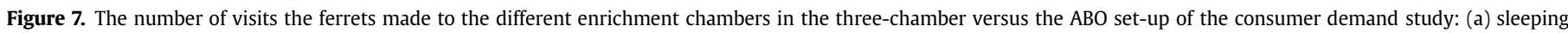

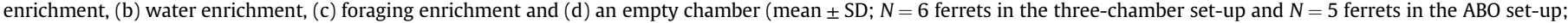
\#indicates an overall difference between the set-ups with $P<0.014$ ).

the environment and thereby reducing unpredictability; Doya, 2008; Inglis, 2000). The more unpredictable 3Ch set-up might have therefore motivated the ferrets to push harder for and make more and longer visits to both chambers and interact more with the enrichments in the chambers. In this case, the results would not reflect the motivation the ferrets have to access the items in the chamber, but would reflect a more general motivation to explore.

\section{Comparison 2: 3Ch Versus ABO Set-up}

The ferrets, as expected, showed a lower motivation to access and interact with the enrichments and paid fewer and shorter visits to the enrichment chambers when enrichments were provided in the home chamber compared to a home chamber without enrichments.

One explanation for these findings is that, in the ABO set-up, the ferrets might have experienced more stimulation and/or satisfaction of their behavioural needs by the preferred enrichments that were freely available in the home chamber. In rats, the provision of enrichment in their home cage lowered exploration behaviour compared to nonenriched rats (Abou-Ismail et al., 2010). The lower motivation for both the enrichment and the empty chamber in the ABO set-up might be a similar effect of the enrichment provided in the home chamber lowering the motivation to explore the environment in search of novelty.

Additionally, in the $3 \mathrm{Ch}$ there was no reason to return to the home chamber except for essential food and water intake, while there was in the ABO set-up. These decreased opportunities for transition between behaviours might have resulted in a longer visit duration in the 3 Ch set-up.

All enrichment categories consisted of alternative (more preferred) ways of presenting resources (i.e. water from a bowl instead of the nipple; food from a foraging ball instead of a bowl; and the opportunity to sleep in a hammock instead of the sawdust) that were already available in the home chamber in both set-ups. Ferrets need to eat and drink multiple times per day, as they have a short intestinal tract (i.e. their gastrointestinal transit time is approximately 3 h, Bleavins \& Aulerich, 1981; Kaufman, 1980) and 

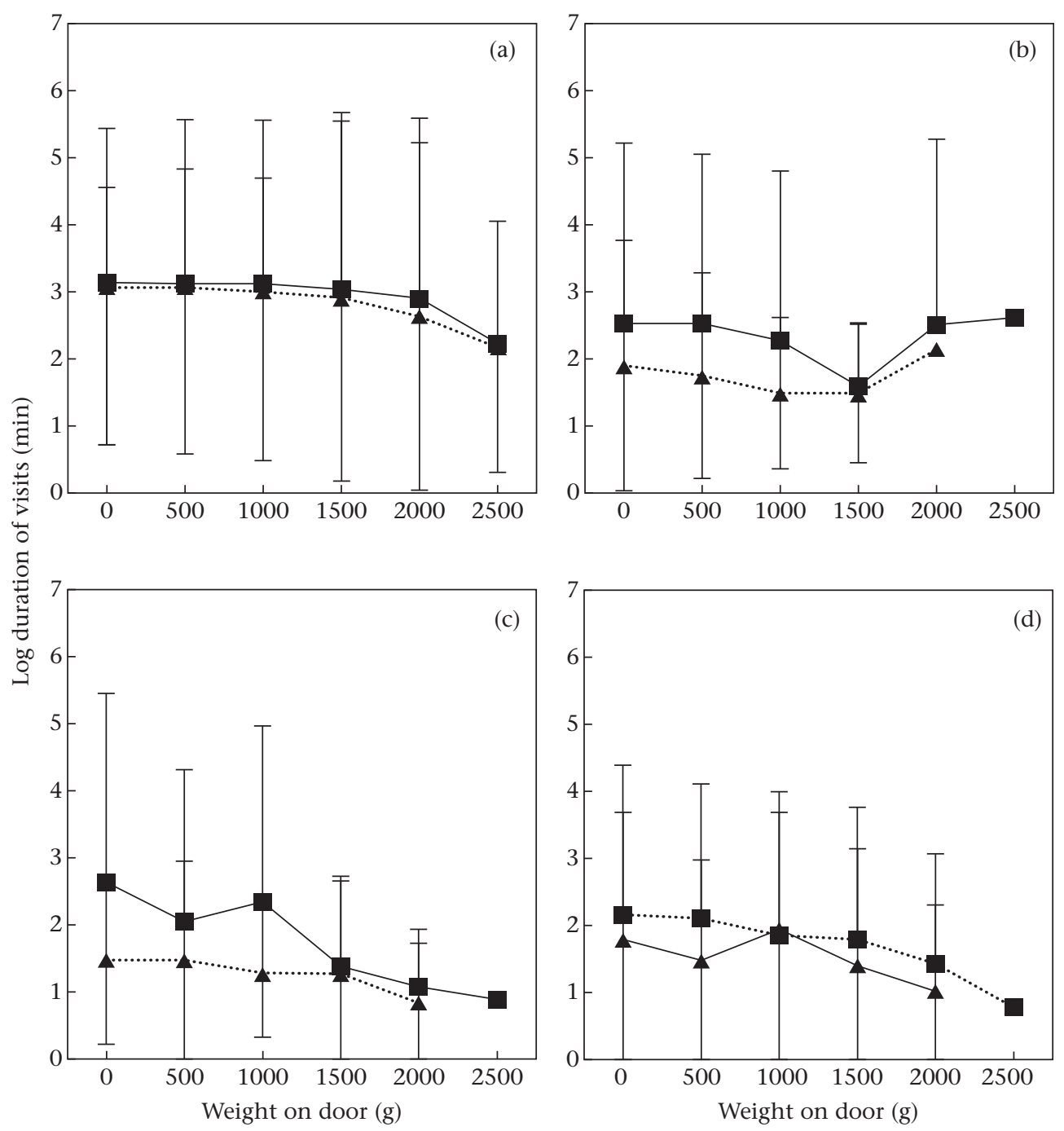

\#

3-chamber $\mathrm{ABO}$

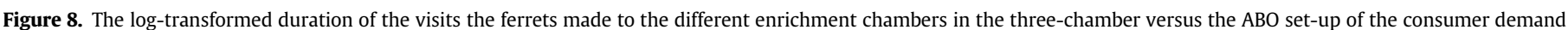

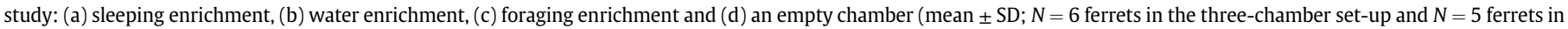
the ABO set-up; \# indicates an overall difference between the set-ups with $P<0.014$ ).

also need a place to sleep multiple times per day, as they are polycyclic sleepers with sleep cycles of $2-4 \mathrm{~h}$ (Marks \& Shaffery, 1996). Therefore, when water and foraging enrichments were tested in the $\mathrm{ABO}$ set-up, the ferrets would frequently return to the home chamber to sleep in the hammock (which was determined to be the most valued enrichment, Reijgwart et al., 2016) after visiting one of the other chambers. As these short behaviours with a high consumption level (number of visits) are thought to be more affected by increasing price than longer lasting behaviours (such as sleeping; Kirkden et al., 2003), they might have been undervalued in the ABO set-up. Additionally, the foraging enrichment could be taken back to the home chamber (which the ferrets did every day) as it was small enough to fit through the cat flap and therefore only had to be worked for once daily, which might have influenced the ferrets' choice in favour of this enrichment.

It should be taken into account that the items from three enrichment categories were being rotated in the ABO set-up: the items from two of the enrichment categories were freely available in the home chamber while the ferret was working to gain access to the items from the third enrichment category. This means that the ferrets had free access to the tested enrichment items before and after the 8day session in which they were asked to work for that specific enrichment category. Therefore, there is a possibility that the ABO set-up cannot be regarded as a closed economy, but as an open economy, lowering the motivation to work for access to the enrichments and violating one of the basic requirements for a reliable consumer demand study (Ladewig et al., 2002; Mason et al., 1998).

\section{Potential Confounding Factors}

There were three unavoidable temporal confounding factors that should be kept in mind when interpreting the results. First, all set-ups were tested in the same sequence, so habituation or deprivation effects could have occurred. If habituation effects took 

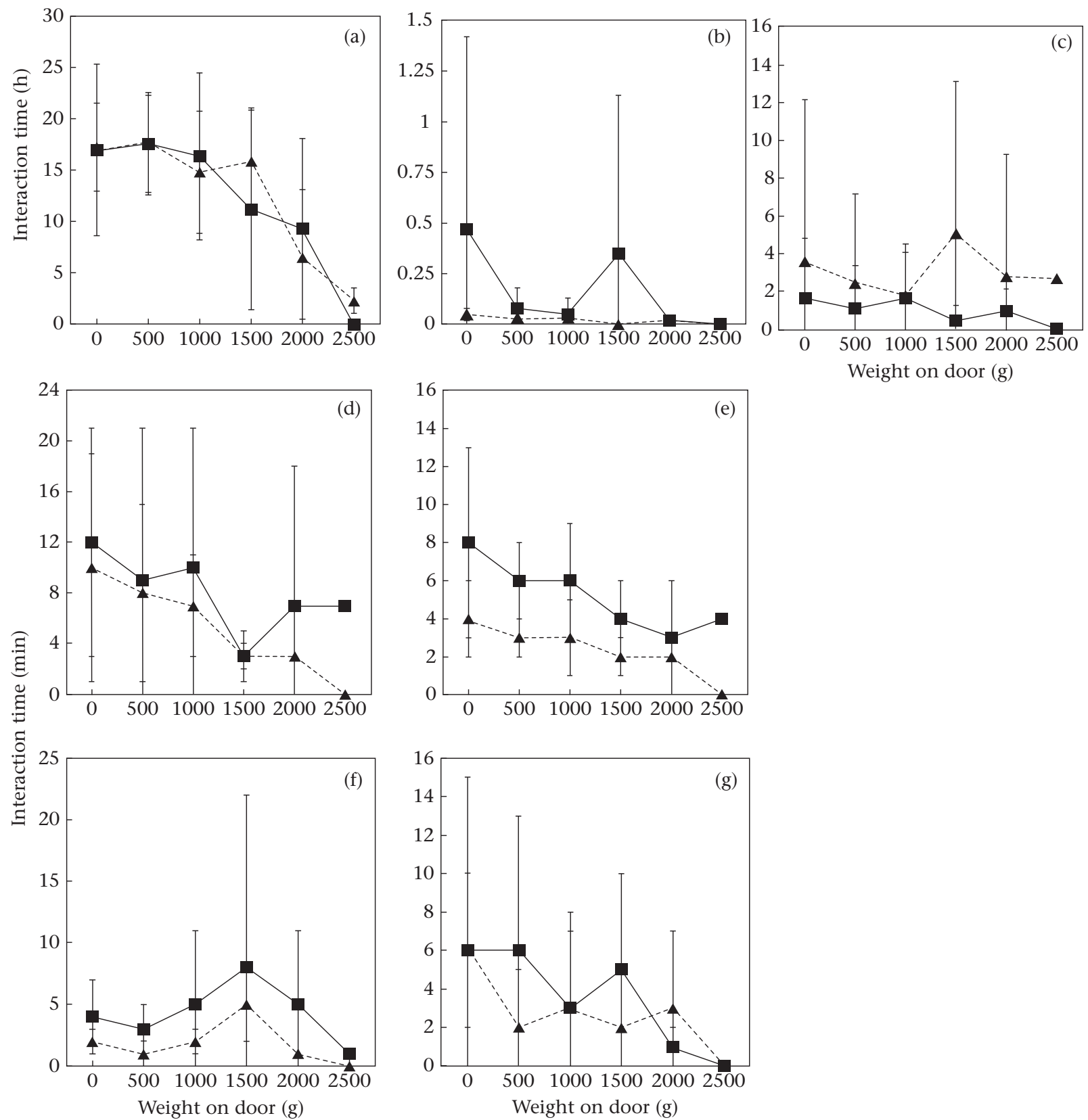

(e)

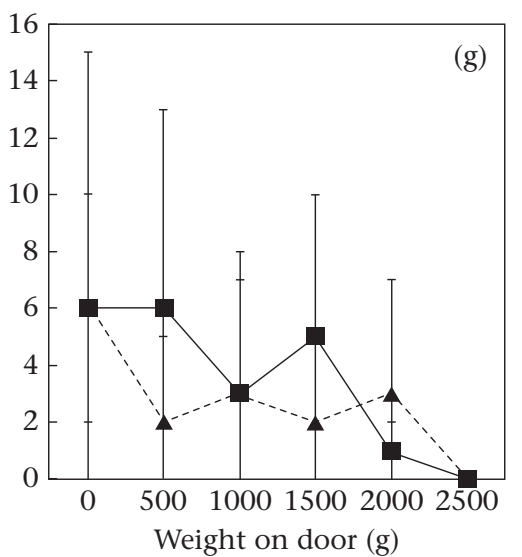

$\#$

3-chamber

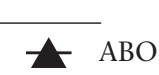

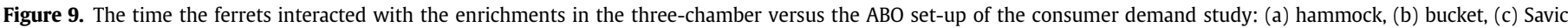

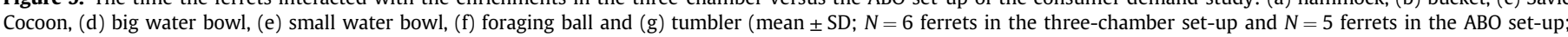
\#indicates an overall difference between the set-ups with $P<0.014$ ).

place, the ferrets would show a lower motivation for the enrichments in subsequent set-ups, whereas if a deprivation effect took place, the ferrets would show a higher motivation for the enrichments in subsequent set-ups (e.g. Latham \& Mason, 2010). We saw the latter pattern in the $3 \mathrm{Ch}$ (i.e. second) set-up compared to the 7Ch set-up, but the first pattern in the $A B O$ (i.e. third) set-up compared to the $3 \mathrm{Ch}$ set-up. These opposite temporal patterns make it difficult to determine whether a habituation and/or deprivation effect were indeed confounding factors in this study. However, these effects could not be avoided, as the three set-ups were built from each other and switching between the 7Ch and
3 Ch set-ups was not only very difficult, but also a great disturbance to the ferrets as it included using power tools and hammers inside the animal room. Additionally, we wanted to provide the ferrets with preferred enrichment items in the ABO set-up, for which we needed the results of the $7 \mathrm{Ch}$ and $3 \mathrm{Ch}$ set-ups.

Second, the price increased continuously within each set-up and for each enrichment, which could affect the animals' motivation as cost and familiarity are increased simultaneously (Seaman et al., 2008). However, presenting costs in a random order has its own disadvantages, as the time at which different costs are imposed and the contrast with previously presented costs both influence the 
demand (Asher, Kirkden, \& Bateson, 2009). As the disadvantages of random costs seem to outweigh those of using ascending costs (Asher et al., 2009), we chose to use the latter approach.

Third, the experiments differed in respect to their duration, as all enrichment categories were tested concurrently in the 7Ch setup, while this was done consecutively in the 3Ch set-up. The only way to create an equal duration for the $7 \mathrm{Ch}$ and $3 \mathrm{Ch}$ set-ups would be to use six times smaller weight increases (i.e. $40 \mathrm{~g}$ instead of $250 \mathrm{~g}$ daily increase in push force) in the 7Ch set-up, which also would have been a confounding factor as it has been shown that the contrast between costs influences an animal's motivation (Asher et al., 2009).

\section{Conclusion}

The results of this study indicate that both ways of providing enrichments concurrently instead of consecutively affect the results of a consumer demand study. In the 7Ch set-up, the animals seemed to consider the resources and time available to them and abandon luxury behaviour and novelty seeking when appropriate. The ABO set-up, on the other hand, could be regarded as an open instead of a closed economy. Overall, using a multichamber set-up (i.e. testing all the enrichment categories concurrently) and keeping the number of items in the home cage to a minimum seem to aid in measuring an animal's motivation for enrichments in a consumer demand study and might, after replication, be added to the best practice guidelines.

\section{Acknowledgments}

This study was funded by a grant of the Ministry of Economic Affairs (EZ) to the Institute for Translational Vaccinology (Intravacc) ('Programma coördinatiepunt alternatieven voor dierproeven'). We thank Kylie Boekelman, Manon van der Meer and Chess Stolk for their help with the execution of the experiments.

\section{References}

Abou-Ismail, U. A., Burman, O. H., Nicol, C. J., \& Mendl, M. (2010). The effects of enhancing cage complexity on the behaviour and welfare of laboratory rats. Behavioural Processes, 85(2),172-180. https://doi.org/10.1016/j.beproc.2010.07.002.

Asher, L., Kirkden, R. D., \& Bateson, M. (2009). An empirical investigation of two assumptions of motivation testing in captive starlings (Sturnus vulgaris): Do animals have an energy budget to 'spend'? and does cost reduce demand? Applied Animal Behaviour Science, 118(3), 152-160. https://doi.org/10.1016 j.applanim.2009.02.029.

Benjamini, Y., Drai, D., Elmer, G., Kafkafi, N., \& Golani, I. (2001). Controlling the false discovery rate in behavior genetics research. Behavioural Brain Research, 125(1), 279-284. https://doi.org/10.1016/S0166-4328(01)00297-2.

Berridge, K. C., \& Robinson, T. E. (2003). Parsing reward. Trends in Neurosciences, 26(9), 507-513. https://doi.org/10.1016/S0166-2236(03)00233-9.

Bleavins, M. R., \& Aulerich, R. J. (1981). Feed consumption and food passage time in mink (Mustela vison) and European ferrets (Mustela putorius furo). Laboratory Animal Science, 31(3), 268-269.

Cooper, J. (2004). Consumer demand under commercial husbandry conditions: Practical advice on measuring behavioural priorities in captive animals. Animal Welfare, 13(1), 47-56.

Cooper, J. J., \& Mason, G. J. (2001). The use of operant technology to measure behavioral priorities in captive animals. Behavior Research Methods, Instruments, \& Computers, 33(3), 427-434. https://doi.org/10.3758/bf03195397.

Dawkins, M. S. (1983). Battery hens name their price: Consumer demand theory and the measurement of ethological 'needs'. Animal Behaviour, 31(4) 1195-1205. https://doi.org/10.1016/s0003-3472(83)80026-8.
Dawkins, M. S. (1990). From an animal's point of view: Motivation, fitness, and animal welfare. Behavioral and Brain Sciences, 13(01), 1-9. https://doi.org/ 10.1017/S0140525X00077104.

Doya, K. (2008). Modulators of decision making. Nature Neuroscience, 11.4, 410-416. https://doi.org/10.1038/nn2077.

Fox, J. G., Bell, J. A., \& Broome, R. (2014). 8: Growth and reproduction. In J. G. Fox, \& R. P. Marini (Eds.), Biology and diseases of the ferret (pp. 187-209). Oxford, U.K.: J. Wiley.

Houston, A., \& McFarland, D. (1980). Chapter 6: Behavioral resilience and its relation to demand functions. In E. Staddon (Ed.), Limits to action: The allocation of individual behavior (pp. 177-203). New York, NY: Academic Press. https://doi.org/ 10.1016/B978-0-12-662650-6.50012-X.

Hovland, A. L., Mason, G., Bøe, K. E., Steinheim, G., \& Bakken, M. (2006). Evaluation of the 'maximum price paid' as an index of motivational strength for farmed silver foxes (Vulpes vulpes). Applied Animal Behaviour Science, 100(3), 258-279. https://doi.org/10.1016/j.applanim.2005.11.006.

Hutchinson, J. (2005). Is more choice always desirable? Evidence and arguments from leks, food selection, and environmental enrichment. Biological Reviews, 80(1), 73-92. https://doi.org/10.1017/S1464793104006554.

Inglis, I. R. (2000). The central role of uncertainty reduction in determining behaviour. Behaviour, 137(12), 1567-1599. https://doi.org/10.1163/156853900502727.

Jensen, M. B., \& Pedersen, L. J. (2008). Using motivation tests to assess ethological needs and preferences. Applied Animal Behaviour Science, 113(4), 340-356. https://doi.org/10.1016/j.applanim.2008.02.001.

Kaufman, L. W. (1980). Foraging cost and meal patterns in ferrets. Physiology \& Behavior, 25(1), 139-141.

Kirkden, R., Edwards, J., \& Broom, D. (2003). A theoretical comparison of the consumer surplus and the elasticities of demand as measures of motivational strength. Animal Behaviour, 65(1), 157-178. https://doi.org/10.1006/anbe.2002.2035.

Kirkden, R. D., \& Pajor, E. A. (2006). Using preference, motivation and aversion tests to ask scientific questions about animals' feelings. Applied Animal Behaviour Science, 100(1), 29-47. https://doi.org/10.1016/j.applanim.2006.04.009.

Ladewig, J., Sørensen, D. B., Nielsen, P. P., \& Matthews, L. R. (2002). The quantitative measurement of motivation: Generation of demand functions under open versus closed economies. Applied Animal Behaviour Science, 79(4), 325-331. https://doi.org/10.1016/s0168-1591(02)00156-9.

Latham, N., \& Mason, G. (2010). Frustration and perseveration in stereotypic captive animals: Is a taste of enrichment worse than none at all? Behavioural Brain Research, 211(1), 96-104. https://doi.org/10.1016/j.bbr.2010.03.018.

Marks, G. A., \& Shaffery, J. P. (1996). A preliminary study of sleep in the ferret, Mustela putorius furo: A carnivore with an extremely high proportion of REM sleep. Sleep, 19, 83-93. https://doi.org/10.1093/sleep/19.2.83.

Mason, G., McFarland, D., \& Garner, J. (1998). A demanding task: Using economic techniques to assess animal priorities. Animal Behaviour, 55(4), 1071-1075. https://doi.org/10.1006/anbe.1997.0692.

Mason, G. J., Cooper, J., \& Clarebrough, C. (2001). Frustrations of fur-farmed mink. Nature, 410(6824), 35-36. https://doi.org/10.1038/35065157.

Matthews, L. R., \& Ladewig, J. (1994). Environmental requirements of pigs measured by behavioural demand functions. Animal Behaviour, 47(3), 713-719. https:// doi.org/10.1006/anbe.1994.1096.

Munksgaard, L., Jensen, M. B., Pedersen, L. J., Hansen, S. W., \& Matthews, L. (2005). Quantifying behavioural priorities-Effects of time constraints on behaviour of dairy cows, Bos taurus. Applied Animal Behaviour Science, 92(1), 3-14. https:// doi.org/10.1016/j.applanim.2004.11.005.

Owen, M. A., Swaisgood, R. R., Czekala, N. M., \& Lindburg, D. G. (2005). Enclosure choice and well-being in giant pandas: Is it all about control? Zoo Biology, 24(5), 475-481. https://doi.org/10.1002/zoo.20064.

Reijgwart, M. L., Vinke, C. M., Hendriksen, C. F., Van Der Meer, M., Schoemaker, N. J., \& Van Zeeland, Y. R. (2015). Workaholic ferrets: Does a two-chamber consumer demand study give insight in the preferences of laboratory ferrets (Mustela putorius furo)? Applied Animal Behaviour Science, 171, 161-169. https://doi.org/ 10.1016/j.applanim.2015.08.032.

Reijgwart, M. L., Vinke, C. M., Hendriksen, C. F., van der Meer, M., Schoemaker, N. J., \& van Zeeland, Y. R. (2016). Ferrets' (Mustela putorius furo) enrichment priorities and preferences as determined in a seven-chamber consumer demand study. Applied Animal Behaviour Science, 180, 114-121. https://doi.org/10.1016/ j.applanim.2016.04.022.

Ross, S. R. (2006). Issues of choice and control in the behaviour of a pair of captive polar bears (Ursus maritimus). Behavioural Processes, 73(1), 117-120. https:// doi.org/10.1016/j.beproc.2006.04.003.

Seaman, S. C., Waran, N. K., Mason, G., \& D'Eath, R. B. (2008). Animal economics: Assessing the motivation of female laboratory rabbits to reach a platform, social contact and food. Animal Behaviour, 75(1), 31-42. https://doi.org/10.1016/ j.anbehav.2006.09.031. 